\title{
\begin{tabular}{l|l} 
Mibraries & DSpace@MIT
\end{tabular}
}

\author{
MIT Open Access Articles
}

In Vitro Hydrodynamic, Transient, and Overtime Performance of a Miniaturized Valve for Hydrocephalus

The MIT Faculty has made this article openly available. Please share how this access benefits you. Your story matters.

Citation: Schwerdt, Helen N., Usamma Amjad, Jennie Appel, Ali M. Elhadi, Ting Lei, Mark C. Preul, Ruth E. Bristol, and Junseok Chae. “In Vitro Hydrodynamic, Transient, and Overtime Performance of a Miniaturized Valve for Hydrocephalus." Ann Biomed Eng 43, no. 3 (March 2015): 603-615.

As Published: http://dx.doi.org/10.1007/s10439-015-1291-x

Publisher: Springer US

Persistent URL: http://hdl.handle.net/1721.1/104086

Version: Author's final manuscript: final author's manuscript post peer review, without publisher's formatting or copy editing

Terms of Use: Article is made available in accordance with the publisher's policy and may be subject to US copyright law. Please refer to the publisher's site for terms of use. 


\section{In Vitro Hydrodynamic, Transient, and Overtime Performance of a Miniaturized \\ Valve for Hydrocephalus}

Helen N. Schwerdt, ${ }^{1}$ Usamma Amjad, ${ }^{2}$ Jennie Appel, ${ }^{1}$ Ali M. Elhadi ${ }^{3}$, Ting Lei ${ }^{3}$, Mark C. Preul, ${ }^{3}$

Ruth E. Bristol, ${ }^{4}$ and Junseok Chae ${ }^{1}$

${ }^{1}$ School of Electrical, Computer, and Energy Engineering, Arizona State University, Tempe, Arizona 85287, USA

${ }^{2}$ School for Engineering of Matter, Transport, and Energy, Arizona State University, Tempe, Arizona 85287, USA

${ }^{3}$ Division of Neurological Surgery, Barrow Neurological Institute, Phoenix, AZ 85013, USA

${ }^{4}$ Department of Neurosurgery, Phoenix Children's Hospital, Phoenix, Arizona 85016, USA

Abbreviated Title: In Vitro Performance of a Miniaturized Valve for Hydrocephalus

Correspondence:

Helen N. Schwerdt

Address:

Koch Institute at MIT

500 Main Street

Cambridge, MA 02139

Phone: (703)401-6959

Email: schwerdt@mit.edu 
Abstract: Reliable cerebrospinal fluid (CSF) draining methods are needed to treat hydrocephalus, a chronic debilitating brain disorder. Current shunt implant treatments are characterized by high failure rates that are to some extent attributed to their length and multiple components. The designed valve, made of hydrogel, steers away from such protracted schemes and intends to provide a direct substitute for faulty arachnoid granulations, the brain's natural CSF draining valves, and restore CSF draining operations within the cranium. The valve relies on innate hydrogel swelling phenomena to strengthen reverse flow sealing at idle and negative pressures thereby alleviating common valve failure mechanisms. In vitro measurements display operation in range of natural CSF draining (cracking pressure, $P_{T} \sim 1-110 \mathrm{mmH}_{2} \mathrm{O}$ and outflow hydraulic resistance, $R_{h} \sim 24-152 \mathrm{mmH}_{2} \mathrm{O} / \mathrm{mL} / \mathrm{min}$ ), with negligible reverse flow leakage (flow, $Q_{O}>-10 \mu \mathrm{L} / \mathrm{min}$ ). Hydrodynamic measurements and over-time tests under physically relevant conditions further demonstrate the valve's operationally-reproducible properties and strengthen its validity for use as a chronic implant.

Key Terms: check valve; hydrocephalus; shunt; hydrogel; cerebrospinal fluid (CSF) draining; intracranial pressure (ICP) regulation; implantable microsystem 


\section{Introduction}

Hydrocephalus (HCP) is a chronic neurological disorder characterized by the inability to sufficiently drain cerebrospinal fluid (CSF), a vital supporting liquid that inundates the brain and which is continuously produced inside the cerebral ventricles (i.e. the choroid plexus). Insufficient drainage causes CSF to accumulate excessively within the cerebral ventricles, which can lead to fatal increases in intracranial pressures (ICP). ${ }^{1}$ The condition can cause abnormal enlargement of the head, convulsions, mental disabilities, and even death. ${ }^{1-3}$ In communicating HCP (where CSF flow remains open between ventricles) this defect in draining is thought to originate due to malfunctioning arachnoid granulations (AGs) that serve as natural valve formations protruding the meningeal membrane surrounding the brain. The AGs normally provide a one-way conduit for CSF transport from the subarachnoid space of the brain into the venous compartment, the sinus, immediately exterior to the meninges and enclosed within the cranium (Figure 1(a)). ${ }^{2}$ In the case of communicating HCP, these AGs may become obstructed and inhibit proper CSF draining.

Standard treatments to safely regulate ICP in hydrocephalus involve implanting a large shunt - comprising a valve with footprints ranging $6.4-7.5 \mathrm{~cm}^{2}$ in area and $0.7-0.8 \mathrm{~cm}$ in height, proximal cerebral catheters ranging $15-23 \mathrm{~cm}$ in length and $0.22-0.25 \mathrm{~cm}$ in outer diameter, and distal catheters having lengths of $90-120 \mathrm{~cm}^{4,5}$ into the brain to divert accumulating CSF through an extensive intracranial tubing (catheter) outside of the skull and to a distal reabsorption area, usually such as the peritoneal or pleural cavities, or right atrium of the heart $^{3,4,5}$ (Figure 1(a)). However, around $40 \%-50 \%$ of these shunts fail within the first two years and must be replaced through multiple additional invasive surgeries. ${ }^{3,6-8}$ Chief complications include mechanical malfunctions, naturally caused obstructions, infections, 
subdural hematomas, overdrainage or underdrainage. Obstructions caused by clogging of the catheters in the cerebral ventricles or distal areas accounts for around $42 \%$ of shunt failures. ${ }^{7}$ Some of these complications may be attributed to the length and location of the tubing. They are also susceptible to external forces, disconnection, breakage, ${ }^{7}$ and/or siphoning effects, ${ }^{9}$ which represents around $21 \%$ of shunt failure cases. ${ }^{7}$ Moreover, the intracranial catheter element may leave the brain exposed to infectious agents. This abundance of failure prone mechanisms emblematic of the current HCP treatment systems illustrates the need for a fundamentally different CSF draining tactic. ${ }^{1,8-11}$ Various methods to improve current shunt techniques have been proposed by incorporation of adaptive elements to control CSF draining rates based on body position ${ }^{12}$ and $\mathrm{ICP}^{13}$. These methods may help reduce over- and under-drainage, but may not be able to address complications arising from physiologically induced obstructions that physically impede CSF draining in proximal catheter implantation sites (eg. ventricles) or in the accumulating areas in the peritoneum space or elsewhere. ${ }^{1}$

An alternative CSF draining solution for communicating HCP is to directly bypass the obstructed AGs and rebuild a CSF route immediately within their vicinity to serve as a standalone AG emulating valve (Figure 1(a)). This synthetic AG would allow for CSF drainage into the venus sinus and remain inconspicuous as it would be cranially concealed. By restricting drainage channels within the confines of the skull, a large proportion of the complications caused by the physical characteristics and placement locations of current shunt systems - infections, externally induced obstructions, siphoning, trauma, etc. - would be mitigated. Such artificial draining mechanisms are realized by embedding a passive miniature valve (synthetic AG) through the meninges in the vicinity of blocked AGs to channel CSF from the subarachnoid space to the sinus in the constituent manner of healthy AGs. In an attempt to replicate normal 
CSF draining processes, the synthetic AG valve must operate with fluid flow properties of actual ventricular CSF draining without any risk for reverse flow leakage and must be permanently stable in operation over the lifetime of the patient. The hydrogel valve described in this study is designed to passively reproduce the ventricular draining operations of normal CSF flow response behavior, while possessing the robust operationally-reproducible qualities required of a permanent medical implant.

\section{Background}

The synthetic AG valve reported herein contrasts from existing miniature valves that may be viewed as candidates in application to HCP treatment, if not for their limitations in overtime reliability and durability, which constrain their use to, mainly, lab-on-a-chip and/or short-term

microfluidics applications. Furthermore, this valve differs from the initially reported AG valve ${ }^{14}$ in fundamental operating principle, design and fabrication, and the ensuing flow characteristics, and operational reproducibility and reliability that only here deliver the targeted properties relevant to actual clinical application, which were not displayed in earlier work. Unlike earlier work, the draining mechanism no longer relies on the pressure-variable deflection height of the membrane, but rather the fixed geometry of the inlet, to produce the desired linear flow characteristics. Alternative design of the valve geometry (a spiral tether instead of a perforated membrane) affords the ability to considerably simplify fabrication process (remove low yield photoresist and release-related steps ${ }^{15}$ to afford higher yield and reproducibility while increasing the robustness of the device.

To replicate the natural draining operations of healthy AG's, the hydrogel valve must essentially function as a check valve, that is, a one-way channel. Further, when the valve is open, 
it should provide the CSF draining fluid flow behavior as in its physical equivalent. That is, the cracking pressure $\left(P_{T}\right)$, flow $\left(Q_{o}\right)$, and fluidic resistance $\left(R_{h}\right)$ should be in range of normal CSF draining. In serving as a uni-directional channel, check valves target 3 basic features: 1) infinite diodicity or only flow $\left(Q_{O}\right)$ in the positive direction $\left.\left(Q_{O} \geq 0\right), 2\right)$ zero flow when the pressure difference across the valve, $\Delta P$, is less than the cracking pressure, $P_{T},\left(Q_{O}=0\right.$ when $\left.\left.\Delta P<P_{T}\right), 3\right)$ a designated non-zero or zero $P_{T}$. Existing miniature check valves suitable for potential use in the proposed enclosed form of hydrocephalus treatment may often fail to maintain stability over longer terms, ${ }^{16}$ in adequately sealing the flow channel during idle $(\triangle P \sim 0)$ and/or negative pressures $(\triangle P<0),{ }^{11,16}$ or involve low reproducibility and highly intricate fabrication processes. ${ }^{17}$

The valve presented here is simple in design (only 3 materials: silicon valve seat, a removable parylene film, and the displacing hydrogel membrane) and fabrication ( 3 basic steps and no release-related processes and no photoresist). This valve relies only on hydrogel swelling phenomena to produce reliable sealing and to secure the valve against leakage, while replicating near natural CSF draining fluid flow behavior. Previously, preliminary work demonstrated the feasibility of the hydrogel valve concept and its capacity in restoring normal CSF draining operations in HCP while providing the robust sealing needed to prevent leakage. ${ }^{14}$ On the other hand, the initial study revealed a few important shortcomings: weak operational-reproducibility and long-term durability — aspects critical for medical implants. The work used photoresist as a sacrificial layer, which is removed at the end of the manufacturing process. However, the use of photoresist was found to compromise the operational stability and functionality of the device. Photoresist exposed an array of problems including: improper and difficult release as sandwiched between membrane and the anchored substrate, adverse reaction with pre-cured hydrogel solutions, and lingering residue obstructed membrane deflection, blocked flow, and/or triggered 
stiction issues. The work presented here resolves these challenges by total reformation of its fabrication and design: the sacrificial photoresist layer is entirely eliminated from the fabrication process along with all associated release-related steps, and the perforated membrane has been replaced with a stress-relief spiral flexure. Through bench top measurements, this new hydrogel valve reveals the targeted fluid flow response behavior in range of normal CSF draining. Furthermore, the valve's in situ feasibility is substantiated by measurements of its dynamic behavior in response to physiologically relevant hydrodynamic fluid flow waveforms in vitro. Finally, its practical applicability as a permanent medical implant may find greater validity through the results obtained in extended in a semi-accelerated hydrodynamic environment emulating amplified pulsatile CSF drainage behavior.

\section{Materials and Methods}

\subsection{Operation}

\subsubsection{Goals and requirements}

To restore physiological CSF circulation mechanisms to the HCP afflicted brain, the hydrogel valve targets reproducing normal CSF flow characteristics of the healthy brain. To begin with, blood should not drain backwards into the brain from the sinus, implying that the check valve should display zero back flow and leakage regardless of pressure. During positive pressure differentials, venous drainage is linear as conveyed by its outflow resistance, $R_{h}$, which ranges from $81.5-136 \mathrm{mmH}_{2} \mathrm{O} / \mathrm{mL} / \mathrm{min}$ as observed in normal subjects. ${ }^{9,10}$ Actual ventricular drainage related parameters, fluctuates considerably, where CSF outflow rates range $Q_{o} \approx 0-3.0$ $\mathrm{mL} / \mathrm{min}$ while intracranial pressure (ICP) ranges from -100 to $350 \mathrm{mmH}_{2} \mathrm{O}$ in normal individuals and to $500 \mathrm{mmH}_{2} \mathrm{O}$ in $\mathrm{HCP}$ patients. ${ }^{1,9,10}$ In addition to emulating normal drainage, the valve 
may also require incorporation of a finite cracking pressure, $P_{T}$, as implemented in current shunts having $P_{T} \approx 10-230 \mathrm{mmH}_{2} \mathrm{O}$, which varies on an individual basis. ${ }^{1,8}$ On top of these timeinvariant characteristics, drainage usually involves a spectrum of dynamic temporal waveforms related to regular cardiac and respiratory cycles, as well as less stable transients during walking, sleeping, coughing, etc., which can span frequencies ranging from 0.0055 (SLOW waves related to heart rate) to $1.2 \mathrm{~Hz}$ (pulse). ${ }^{10}$ Therefore, the transient behavior of the valve must be considered and must at least respond sufficiently fast to prevent finite reflux leakage and to activate drainage during abrupt pressure spikes without impacting overall performance and longevity. Finally, the device must be rendered on biocompatible materials and match the structural requirements to be surgically installed without significant protrusion.

\subsubsection{Basic operation}

The valve entails deflection of a simple circular hydrogel diaphragm anchored by flexures to a silicon substrate (Figure 1(b)). Both silicon and hydrogel elements are proven biocompatible materials. ${ }^{18-20}$ In the closed state, when $\Delta P<P_{T}$, the hydrogel diaphragm lies atop and caps the silicon orifice to block outflow $\left(Q_{O}=0\right)$. The liquid induced swelling behavior of the hydrogel provides a pre-induced sealing force between the hydrogel diaphragm and silicon seat and orifice, effectively establishing a threshold for valve opening (ie. $P_{T}$ ). The hydrogel membrane remains swollen as it is immersed in a liquid at all times and securely seals the orifice to prevent any leakage during closed and idle states. The strength of this self-induced seal along with $P_{T}$ may be controlled by adjusting the spring constant of the flexure supported diaphragm, which may involve changing its hydrogel material's properties (ie. relative elasticity) and/or

geometry. ${ }^{15,21-25}$ In the open state, when $\Delta P \geq P_{T}$, the spiral flexures bend upwards in response to 
increasing pressure between inlet $\left(P_{i}\right)$ and outlet $\left(P_{o}\right)$, lifting the diaphragm from the substrate and allowing fluid to flow out through the via and traverse around the diaphragm. During this open state, steady state outflow rates are for the most part (the exposed drainage area between the orifice and the deflected membrane is much larger than the area of the orifice for marginal $\Delta P)$ governed by the size of the silicon orifice, which acts as a linear hydraulic resistance, as desired. The spiral flexure design relieves in-plane stresses caused by the lateral expansion of the hydrated hydrogel and maximizes out-of-plane axial swelling to strengthen sealing.

\subsection{Design}

The valve consists of a center circular hydrogel diaphragm hinged to three flexure supports that spiral 90 degrees around the diaphragm and anchor to the silicon substrate and is designed to provide linear flow operation as well as minimal reverse flow leakage. The geometry of the valve is shown in Figure 2(a) and its dimensions in Table 1. In this section, analyses will be given for: (1) the flow behavior of the flexure diaphragm valve and its design criteria to display the targeted linear flow response throughout the most part of CSF draining, followed by (2) the sealing strength provided by hydrogel swelling characteristics to prevent back flow leakage and provide a non-zero positive cracking pressure $\left(P_{T}>0\right)$ for valve opening.

The minimum pressure differential $\left(\Delta P_{\min }\right)$ required for full valve opening or displacing the membrane to a height $\left(w_{\min }\right)$ where the outflow resistance becomes linear will be estimated to ensure a geometry that provides linear flow readily within a small $\Delta P$ relative to expected operating $-100<\Delta P<500 \mathrm{mmH}_{2} \mathrm{O}$. For an incompressible fluid, fluid flow rate $\left(Q_{o}\right)$ through the valve may be modeled by a linear expression, $Q_{O}=\Delta P / R_{h}$, where $R_{h}$ is hydraulic resistance. In the case of a deformable membrane valve, $R_{h}$ may be modeled as a summation of series resistors 
comprising the fixed inlet orifice resistance $\left(R_{\text {inlet }}\right)$, the variable displacement resistance formed by membrane deflection $\left(R_{w}\right)$, and the resistance of the channels formed by the exposed area between flexures (perforations). The latter perforation area is much larger, by a factor of $>10$, than the area of the former two and therefore can be disregarded for the succeeding approximations. The resistance of the circular inlet orifice is expressed as, ${ }^{26}$

$$
R_{i}=\frac{8 \mu L_{i}}{\pi r_{i}^{4}}
$$

where $\mu$ is dynamic viscosity of the fluid $\left(\mu(\right.$ water $) \approx 1.002 \mathrm{mPa} \cdot \mathrm{s}$ at $20^{\circ} \mathrm{C}$ and $\approx 0.68 \mathrm{mPa} \cdot \mathrm{s}$ at $38^{\circ} \mathrm{C}$, and $\mu(\mathrm{CSF}) \approx 0.72 \mathrm{mPa} \cdot \mathrm{s}$ at $\left.38^{\circ} \mathrm{C}\right),{ }^{27} r_{i}$ is the radius of the silicon inlet orifice, and $L_{i}$ is the length of the orifice or substrate thickness $(500 \mu \mathrm{m})$. The variable displacement resistance may be approximated to a rectangular orifice and expressed by,

$$
R_{h}\left(h_{o}\right) \approx \frac{12 \mu L_{o}}{w_{o} h_{o}^{3}\left(1-0.630 h_{o} / w_{o}\right)},
$$

where $L_{o}$ is the channel length formed by the outer edge of the hydrogel center diaphragm and the outer edge of the silicon inlet orifice along the longitudinal axis of the substrate $\left(L_{o}=r_{o}-r_{i}\right)$, $w_{o}$ is the channel width or cylindrical circumference formed by the silicon orifice $\left(w_{o}=2 \pi r_{i}\right)$, and $h_{o}$ is channel height formed by the deflection of the membrane $\left(h_{o} \approx w_{z}\right)$. Upon increasing $\Delta P$, and hence $w$, outflow resistance will further become determined by the fixed size and resistance of the inlet orifice $\left(R_{i}\right)$, rather than by the variable membrane gap, and the valve will obtain the desired linear drainage characteristics. Full valve opening is defined here as the case when membrane deflection, $w_{z}$, exposes a lateral channel for fluid transport such that the resistance generated by this displacement channel, $R_{w}$, is equal to the resistance at the inlet, $R_{i}$. By equating $R_{i}=R_{h}$, and approximating $w_{o}=2 \pi r_{i}>h_{o}$, the minimum deflection required for full valve opening is, 


$$
w_{\min } \approx\left(\frac{3 L_{o} r_{i}^{3}}{4 L_{i}}\right)^{1 / 3}
$$

Based on the preceding fluidic models for channel requirements, beam bending equations may then be used to estimate the deflection of the valve diaphragm ${ }^{21}$ and ensure the valve can open readily upon positive pressure differentials such that a linear flow is generated as intended by the fixed hydraulic resistance. As these models are for determining the minimum pressure, $\Delta P_{\min }$, that provides full valve opening, only the maximum displacement or deflection at the diaphragm itself is considered. Based on this simplification, the maximum deflection is equated to $w_{z}=F / k_{z}$, where $F$ is the applied force vertical to the diaphragm and $k_{z}$ is the spring constant of the flexures. The spiral flexures may be approximated as cantilever beams having individual spring constants of, $k_{z, \text { beam }}=\frac{E W t^{3}}{L^{3}}$, where $E$ is Young's modulus $(\sim 100-900 \mathrm{kPa}$ for liquid infused HEMA-based hydrogels) ${ }^{22,24}, W$ is beam width, $t$ is thickness, and $L$ is length. This results in a flexure spring constant of three times the beam's spring constant, $k_{z}=\frac{3 E W t^{3}}{L^{3}}$, for the three flexure supported diaphragm. The applied force is simply, $F=\Delta P \cdot A=\Delta P \cdot \pi r_{i}{ }^{2}$. Correspondingly, center membrane displacement is,

$$
w_{z}=\frac{F}{k_{z}}=\frac{3 \Delta P \pi r^{2} L^{3}}{E W t^{3}}
$$

By rearranging terms in (4) and substituting $w_{z}$ with $w_{\min }$ from (3), the minimum pressure across the membrane required to provide this full valve opening is,

$$
\Delta P_{\min }=\frac{k_{z} w_{\min }}{\pi r_{i}^{2}}=\frac{E W t^{3}}{3 \pi r_{i}^{2} L^{3}}\left(\frac{3 L_{o} r_{i}^{3}}{4 L_{i}}\right)^{1 / 3}
$$


Based on physical design parameters (Table 2), $\Delta P_{\min } \approx 4 \mathrm{mmH}_{2} \mathrm{O}$, for larger membranes $(L=2$ mm) up to $\Delta P_{\text {min }} \approx 25 \mathrm{mmH}_{2} \mathrm{O}$ for smaller membrane devices $(L=1.45 \mathrm{~mm})$, which ranges considerably smaller than the actual ventricular $\Delta P$ that may reach up to $500 \mathrm{mmH}_{2} \mathrm{O}$, as well as standard designated shunt cracking pressures of $P_{T} \approx 10-230 \mathrm{mmH}_{2} \mathrm{O}$. Therefore, since $\Delta P_{\min }$ is much smaller than the operating $\Delta P$ range, the valve is expected to be completely open for the most part of draining operations, meaning that outflow resistance is mostly fixed and dictated by inlet dimensions to display desired linear flow behavior.

In the valve's closed state, when the differential pressure between SAS and draining region is less than the cracking pressure $\left(\Delta P<P_{T}\right)$, the strength of the reverse leakage seal and the cracking pressure are related to valve geometry and hydrogel material properties. hydrogel stiffness $(E)$ and swelling ratio $(\% S)$ is predominantly governed by its chemical constituency, and by Flory theory and its extensions the volumetric swelling ratio is, ${ }^{23}$

$$
\left(\frac{V}{V_{0}}\right)^{-2 / 3} \approx \frac{k}{\zeta Z},
$$

where $V$ and $V_{0}$ are swollen and dry gel volumes, respectively, $k$ is gel elasticity, $\zeta$ is degree of gel ionization, and $Z$ is potential ions per dry gel volume. Flory theory also infers a linear relationship between $k$ and the ratio of crosslinker (EGDA). In consequence, the hydrogel swelling is to the $(-2 / 3)$ power proportional to crosslinker ratio and this swelling dependence may be used to estimate valve $P_{T} . P_{T}$ may be coarsely estimated by rearranging (1) to solve for pressure $(P)$ as a function of the lateral expansion $\left(w_{z}\right)$ caused by hydrogel expansion. This approximation may negate the effects of radial expansion and substrate boundaries that will decrease $P_{T}$. To address this limitation, the diaphragm is made sufficiently thick relative to its diameter to offset vertical displacements caused by lateral swelling-induced stresses concentrated at the anchors. Further, spiral flexures are used to equilibrate radial swelling and eliminate the 
potential buildup of residual stress, thereby removing potential buckling issues. Based on the preceding expectations, and technical fabrication-related limitations, the thickness is set at a range of $t=200-500 \mu \mathrm{m}$.

\subsection{Fabrication}

The fabrication of the hydrogel valve entails standard micromachining and photolithography processes on a $500 \mu \mathrm{m}$ thick $\mathrm{Si}<100>$ substrate and involves only three basic steps. First, plasma enhanced chemical vapor deposition (PECVD) is used to deposit a conformal $150 \mathrm{~nm} \mathrm{SiO}_{2}$ layer on the topside of the substrate. This oxide film will serve to strengthen adhesion of subsequent hydrogel anchors. Following typical adhesion promotion procedures for parylene-C to silicon, a conformal $100 \mathrm{~nm}$ film of parylene- $\mathrm{C}$ is deposited atop this oxide layer and then patterned using $\mathrm{O}_{2}$ plasma at $150-200 \mathrm{~W}$ to create a negative pattern for the hydrogel anchors. The parylene layer provides low surface energy to the moveable parts of the hydrogel diaphragm. To enhance adhesion between hydrogel and the oxide anchor patterns, wafers are immersed in an aqueous $\gamma$-MPS solution overnight followed by $\mathrm{H}_{2} \mathrm{O}$ rinsing and dehydration baking. ${ }^{28}$ Following adhesion promotion, the hydrogel solution is poured onto the wafers and confined at the edges by $200-500 \mu \mathrm{m}$ thick rubber spacers that will also fix the vertical separation between the mask and substrate and subsequent hydrogel thickness. The hydrogel is synthesized using a chemical composition of the monomer, 2-hydroxyethyl methacrylate (HEMA), crosslinker, ethylene glycol dimethacrylate (EGDA), and photoinitiator, 2,2dimethoxy-2-phenylacetophenone (DMPA), at a volumetric ratio of 1.0/0.04/0.1. UV exposure through the mask cures and patterns the hydrogel valves. Finally, the third step is to form the inlet orifice by deep reactive ion etching (DRIE) the backside of the Si substrate. Residing 
topside exposed $\mathrm{SiO}_{2}$ and parylene are etched using buffered hydrofluoric acid and $\mathrm{O}_{2}$ plasma, respectively. The fabrication process and hydrogel valve are shown in Figure 2.

\section{Results}

\subsection{Experimental setup}

Benchtop testing of the hydrogel valve encompassed three sets of measurements: (1) basic hydrodynamic characteristics or pressure-flow response in vitro, (2) transient response, and (3) overtime performance under semi-accelerated conditions. Unless otherwise noted, all fluidic experiments were performed in simulated CSF (phosphate buffered saline, PBS, an aqueous solution consisting of $(\mathrm{g} / \mathrm{L}) 8 \mathrm{NaCl}, 0.2 \mathrm{KCl}, 1.44 \mathrm{Na}_{2} \mathrm{HPO}_{4}, 0.24 \mathrm{KH}_{2} \mathrm{PO}_{4}$ or artificial CSF, aCSF, an aqueous solution of $(\mathrm{g} / \mathrm{L})$ of $8.66 \mathrm{NaCl}, 0.244 \mathrm{KCl}, 0.206 \mathrm{CaCl}_{2} \cdot 2 \mathrm{H}_{2} \mathrm{O}, 0.163$ $\mathrm{MgCl}_{2} \cdot 6 \mathrm{H}_{2} \mathrm{O}, 0.214 \mathrm{Na}_{2} \mathrm{HPO}_{4} \cdot 7 \mathrm{H}_{2} \mathrm{O}, 0.027 \mathrm{NaH}_{2} \mathrm{PO}_{4} \cdot \mathrm{H}_{2} \mathrm{O}$ ) replicating the ionic consistency ( $\mathrm{pH}$ 7.4) of its physiological counterpart and containing $10 \%$ blood (defribinated sheep blood, Quad Five, Materials Bio Inc.) to exemplify situations of cerebral infections, trauma, and/or infarction of blood-containing particles. ${ }^{29-32}$ Temperature was maintained at $\sim 38-40{ }^{\circ} \mathrm{C}$ by submerging the setup into a constant temperature water bath to emulate the warmer implant brain setting. The inlet pressure, $P_{i}$, outlet pressure, $P_{o}$, and $\Delta P$ across the valve were measured by amplifying and converting voltage output from a differential pressure transducer (PX26-001DV, Omega) with $1 \%$ accuracy, and linearity from $-700<P<700 \mathrm{mmH}_{2} \mathrm{O}$ with $\sim 1 \mathrm{mmH}_{2} \mathrm{O}$ resolution. Calibration of the pressure sensor revealed a slope of $\sim 44.55 \mathrm{mmH}_{2} \mathrm{O} / \mathrm{mV}$ with a coefficient of determination value, as obtained from a fitted linear regression model, of $R^{2}=$ 0.9994. $Q_{O}$ was measured by recording the differential pressure across a fixed fluidic resistance: a $7 \mathrm{~cm}$ long rigid pipe having an inner diameter of $0.25 \mathrm{~mm}$, whic was calibrated with a syringe 
pump input and displayed linearity from $-700<Q_{o}<700 \mu \mathrm{L} / \mathrm{min}$ with $\sim 2 \mu \mathrm{L} / \mathrm{min}$ resolution. All amplified voltage for $P_{i}, P_{o}, \Delta P$, and $Q_{O}$ were fed to a data acquisition card and monitored on a computer. The complete setup encompassing the three sets of measurements is shown in Figure 3(a).

Basic hydrodynamic measurements to obtain pressure-flow curves of individual valves along with $P_{T}$ and $R_{h}$, involved inputting discrete levels of flow or pressure and measuring the resulting pressure or flow, respectively. $P_{T}$ was measured by setting the pump source to minimum flow settings $(0.01-0.05 \mathrm{~mL} / \mathrm{min})$ to slowly increase $\Delta P$ across the initially closed valve and record $\Delta P$ as soon as $Q_{O}$ increased. $R_{h}$ was determined by calculating the slope from a linear regression model fitted to pressure-flow data for $\Delta P>P_{T}$ or, equivalently, $Q_{O}>0$.

Transient response experiments were performed by generating pulsatile waveforms through serial programming of the syringe pump to create custom structured time-varying waveforms and/or manual control of the pressure source through physical closing/opening of a mechanical valve to generate rapid binary-like off/on patterns.

The overtime study involved parallel concurrent operation of multiple hydrogel valve devices subjected to pulsatile flow for 3 weeks. Despite a single pulsatile fluid source, all valve devices experienced similar pressure differentials since their outflow resistance and cracking pressures were not significantly different. A peristaltic pump (Masterflex Digital Modular Drive 7592-82) was used to crudely replicate largely amplified and accelerated forms of physiological pressure waves possessing maximum $\Delta P \sim 300-800 \mathrm{mmH}_{2} \mathrm{O}$ and frequency components as high as $1-4 \mathrm{~Hz}$. Instrumentation parameters are given in Figure 3(b).

\subsection{Measurements}




\subsubsection{Basic hydrodynamic valve characteristics}

Basic hydrodynamic measurements display valve operation within range of targeted normal CSF drainage specifications and generally predictable behavior in relation to designed valve geometries as shown in Figure 4. Figure 4(a) shows multiple measurement sets of pressure-flow data for a valve with $t \sim 300 \mu \mathrm{m}, L_{f}=1.45 \mathrm{~mm}, W_{f}=200 \mu \mathrm{m}, r_{o}=550 \mu \mathrm{m}$, and $r_{i}$ $=250 \mu \mathrm{m}$. Measurements were initially performed in water at $\sim 23{ }^{\circ} \mathrm{C}$ using the two different input sources (pressure via water column and flow via syringe pump) to validate the negligible impact of source selection and also the nearly uniform operational behavior of the valve. Measurements of the valve introduced in the emulated CSF with $10 \%$ blood at $\sim 38-40{ }^{\circ} \mathrm{C}$ shifts operation to a lower $R_{h}$ as expected based on the lower viscosity of the heated in vitro fluid $(\sim 0.72 \mathrm{mPa} \cdot \mathrm{s})$ relative to that of water at $23{ }^{\circ} \mathrm{C}(\sim 0.936 \mathrm{mPa} \cdot \mathrm{s}) .{ }^{27}$ Figure 4(b) shows measurements for a larger valve geometry with $t \sim 250 \mu \mathrm{m}, L_{f}=2 \mathrm{~mm}, W_{f}=200 \mu \mathrm{m}, r_{o}=600$ $\mu \mathrm{m}$, and $r_{i}=250 \mu \mathrm{m}$ tested in three different working environments (water, 10\% aqueous microparticle suspension, and aCSF). The latter valve displays less variation that is likely owing to its larger size. Figure 4(c) displays data on the measured $P_{T}$ and $R_{h}$ for different valve geometries and the two different liquid environments. As anticipated, valves with smaller $r_{i}$ exhibit a higher $R_{h}$ and those with smaller overall dimensions (small $L_{f}$, and $r_{o}$ ) exhibit a higher $P_{T}$. However, in contrast to expectations, the values of $R_{h}$ are not established absolutely by the $r_{i}$ dimension. As will be discussed in subsequent sections, the impact of poorly defined hydrogel lingering in exposed outlet perforations is pronounced and effectively acts as a supplementary linear outflow resistance. Valves operated in vitro display a lower $R_{h}$ relative to water at $23{ }^{\circ} \mathrm{C}$, but this does not scale directly with viscosity $(\sim 77 \%)$, as would be expected based on expressions (1) and (2), but seems to scale by $\sim 25-36 \%$. On the other hand, $P_{T}$ variation is less 
predictable, but still lies within the targeted range of operation. A summary of measured specifications in comparison to targeted performance criteria is shown in Table 2.

\subsubsection{Transient response}

Transient behavior of the hydrogel valve was investigated by observing the fluid flow response for controlled time-varying flow inputted waveforms and abrupt changes in steep pressure gradients using manual valve control of a pressure source input. All transient measurements were performed in the emulated CSF solution with $10 \%$ blood at $\sim 38-40{ }^{\circ} \mathrm{C}$ using a larger valve with $t \sim 300 \mu \mathrm{m}, L_{f}=2 \mathrm{~mm}, W_{f}=200 \mu \mathrm{m}, r_{o}=600 \mu \mathrm{m}$, and $r_{i}=250 \mu \mathrm{m}$. Figure 5(a) displays plotted temporal response of a valve for triangular-like spike waveforms at a frequency of $0.1 \mathrm{~Hz}$ as generated by a programmed syringe pump. $Q_{O}$ closely traces the pressure waveforms during the valve's open state when $\Delta P=P_{i}-P_{o}>0$. As soon as $\Delta P=0, Q_{O}$ approaches zero, and closes within $\sim 2 \mathrm{~s}$ (as may be seen in the inset of Figure 5(a) magnifying when $\triangle P$ reaches zero and $Q_{O}$ reaches zero). This lag is most likely due to the inertance introduced by the narrow flow sensor (a $250 \mu \mathrm{m} \times 7 \mathrm{~cm}$ pipe connected downstream to the valve device and pressure sensor), estimated at $\sim 4 \mathrm{mmH}_{2} \mathrm{O} \cdot \mathrm{min}^{2} / \mathrm{mL}$, which acts to oppose accumulating fluid flow from larger channels $(\sim 1.59 \mathrm{~mm}$ x $10-20 \mathrm{~cm}$ pipe $)$ connected between the device and flow sensor that collectively introduce a time constant of $\sim 2$ s. Figure 5(b) displays the transient behavior for more rapid and sharp changes using a pressure source (a water column with a height of $\sim 240 \mathrm{mmH}_{2} \mathrm{O}$ ) to observe valve opening dynamics. The valve is responded virtually instantly when $\Delta P>0$, demonstrating its ability to safely drain in the event of rapid pressure spikes that may occur naturally (eg. coughing, running, etc.). ${ }^{10}$ 


\subsubsection{Overtime performance}

Measurements of basic hydrodynamic characteristics were performed at weekly intervals for a span of three weeks for valves continuously operating in the emulated CSF solution consisting of $10 \%$ blood and at $~ 38-40{ }^{\circ} \mathrm{C}$ under sustained pulsatile flow (Figure 3). Weekly pressure-flow response measurements for the valve with $t \sim 300 \mu \mathrm{m}, L_{f}=1.45 \mathrm{~mm}, W_{f}=200$ $\mu \mathrm{m}, r_{o}=550 \mu \mathrm{m}$, and $r_{i}=250 \mu \mathrm{m}$ are shown in Figure 6(a). Hydrodynamic measurements were taken three times at each interval. The collected data was also analyzed to determine $R_{h}$ and $P t$ for individual sets of measurements to quantify relative variation in performance (Figure 6(b)). The deviations seen in $R_{h}$ and $P_{t}$ overtime may be deemed trivial relative to the deviations observed for operation in water prior to prolonged operation.

\subsubsection{Surgical implantation in human cadaveric head}

In order to determine optimal location and methods to affix the valve for continuous CSF drainage, placement was performed in a formalin-fixed and vascular structure silicone-injected cadaveric human head. The experiments were conducted at the Neurosurgery Research Laboratory of the Barrow Neurological Institute on lightly formalin solution-fixed, siliconinjected cadaver heads and brain specimens (red silicone into arteries, blue silicone into veins) without obvious intracranial disease. A grommet made of biocompatible silicone material and having an outer diameter of $12 \mathrm{~mm}$ was molded around the silicon-based valve die. The grommet provides the structural form to easily and securely position and lock into the dural wall where an aperture has been created to abdicate CSF draining to the grommet-affixed implant valve, as designated by the specialist. The grommet further provides the mechanical matching between the hard implant substrate and the softer brain material, along with softening any sharp edges and 
corners of the silicon substrate. This surgically-installable grommet was made in-house at Arizona State University. Valve implant feasibility must be addressed to guarantee that its physical form accommodates to the access and appending of the valve in the intradural surface of the superior sagittal sinus in humans. The valve is intended to be implanted at the meningeal wall of the sagittal sinus, free from choroid plexus as frequently seen as a mechanism for failure in current shunts. Initial feasibility experiments demonstrated that the optimal placement of the hydrogel valve would be towards the front of the head where the sagittal sinus occupies a larger volume free from bridging veins that would make the surgical procedure more difficult (Figure 7). However, smaller grommet fixtures may be desirable to aid in implantation due to the limited visibility characteristic of the size of the surgical incision created for the valve. Optimization of the surgically friendly interface is to be performed in future work.

\subsection{Discussion}

Based on measurements, the hydrogel valve demonstrates targeted linear flow behavior in range of physiological CSF drainage parameters (Figure 4), the ability to respond readily to timevarying flow or pressure differentials (Figure 5), and the potential longevity qualities required for implant application (Figure 6). Through hydrogel swelling mechanisms, the valve is capable of sealing and preventing back flow leakage during idle pressures such that a finite negative pressure differential is not required to seal the valve. Despite the subdued mathematical rigor used to model valve hydrodynamics, there are few areas of clear discrepancy between measurements and expressed theory. One instance is the higher $(5-10 \mathrm{x}) R_{h}$ displayed among valves in comparison to the theoretical resistance of the silicon orifice $\left(\sim 1-5 \mathrm{mmH}_{2} \mathrm{O} / \mathrm{mL} / \mathrm{min}\right)$ 
that was intended to dominate outflow resistance. This deviation is due to lingering improperly patterned hydrogel bordering all of the unexposed hydrogel areas (flexures and diaphragm) and effectively widening flexures while narrowing the exposed out-of-plane outflow area. These effects may be introduced into the model by adding a series resistance to the $R_{i}$, inlet orifice resistance. Nevertheless, the nonuniform residing hydrogel may also hinder the operational reproducibility of the valve since this hydrogel is not always firmly attached to the main diaphragm and possesses irregular thicknesses. This irregularity is attributed to equipment limitations in the photopatterning step during fabrication, but may be easily overcome by using a more coherent UV source and minimizing light scattering in the hydrogel medium. Well defined high aspect ratio hydrogel structures have been reported and these techniques may be implemented to sharpen hydrogel valve patterns as well as create thicker structures to strengthen sealing. ${ }^{33}$

Even with the preceding issues, the valve still maintains relatively low operational variation, as displayed by the nearly overlying pressure-flow response data for different working fluid environments (Figure 4) and for prolonged operations (Figure 6), which is almost equivalent to its commercial shunt counterpart. ${ }^{9,10}$ Overtime measurements, as shown in Figure 6 demonstrate the ability of the valves to maintain their basic draining functionality without noticeable degradation in back flow sealing properties despite experiencing larger than the average naturally-occurring pressure differentials (as high as $800 \mathrm{mmH}_{2} \mathrm{O}$ ) occurring more than 10x faster than normal respiratory- or cardiac-originating rhythmic ventricular waves. The overtime reproducibility observed in these valves clearly contrast with the less stable performance seen in prior work, ${ }^{14}$ where photoresist-induced stiction and/or poor mechanical stability of the hydrogel membrane degraded the valve's capability to provide consistent draining 
characteristics to operate continuously without leakage. The ability of the valves to preserve their hydrodynamic characteristics under these highly amplified conditions may give initial insight as to their longevity properties and ability to permanently drain CSF safely for the lifetime of the HCP afflicted individuals.

In addition to the mechanical performance of the valve, the slightly higher physiological $\mathrm{pH}$ and ionic properties of the artificial CSF liquid do not seem to degrade the hydrogel material. In the real operating setting of the pathological CSF physiology, proteins in CSF may adsorb onto the hydrogel membrane and impact valve operation. ${ }^{29}$ Protein adsorption is also believed to influence blockage of current commercial shunts, ${ }^{30}$ while other studies have shown that blood cells have a more noticeable impact on shunt performance. ${ }^{31}$ Any surface interactions or spoliation of blood particulates did not seem to prominently affect valve sealing in measurements, thus far, in contradiction to prevalent and expected concerns. On the other hand, the heterogeneous solutions used in measurements may have influenced $P_{T}$ and $R_{h}$ by the wedging and accumulation of small particulates in the crevices of the hydrogel valve. The possible consequences of this wedging may be overshadowed by the lower viscosity of the heated environment and/or may be inconsequential since the size of these particulates is largely smaller than the hydrogel valve. ${ }^{34}$ Furthermore, the effects of proteins cannot be disregarded especially given the hydrophilic properties of the hydrogel material which may adsorb more proteins $^{29}$ in contrast to more hydrophobic silicone based materials used in existing shunts. Despite the addition of blood, which contains a much larger concentration of proteins than CSF, a direct measure of the relationship between protein concentrations and valve operation would be needed in the future to account for the largely fluctuating and relatively higher concentrations of proteins in CSF of infants. ${ }^{32}$ Longer term studies may be needed to account for the adsorption 
and adherence of proteins and/or blood particles on the hydrogel membrane, which may impact operation overtime.

One area of speculation is the required $R_{h}$ of the introduced artificial CSF draining valve, since the physiological $R_{h}$ of healthy humans may not be the same as the one needed by HCP suffering individuals. This is also discerned in currently used shunt treatments that implement a finite $P_{T}$, not physically inherent in sinus draining but required to offset the effects of siphoning

caused by the elongated shunt catheters, and lower $R_{h}$ than those observed in normal subjects. ${ }^{9,10}$ These uncertainties can be resolved when the valve is tested in live subjects, such as animals induced with HCP.

\section{Conclusion}

The miniature hydrogel valve presented here has been shown to operate with targeted hydrodynamic specifications $\left(R_{h} \sim 24-152 \mathrm{mmH}_{2} \mathrm{O} / \mathrm{mL} / \mathrm{min}\right)$ and the desired self-sealing properties to possess negligible leakage. The valve may be a safer alternative to current shunt treatments for HCP as demonstrate by its ability to sustain draining mechanisms under prolonged operation in heavily exaggerated physiological working conditions. The valve is simple in both design and fabrication, and only comprises two or three materials, silicon, hydrogel, and parylene, all of which are biocompatible. These results serve to strengthen the valve's potential application in treating HCP in a safer and more robust manner than current treatment protocols. Future work to ensure its reliability and ability to drain CSF in sentient brains will entail in vivo testing in animal models. 


\section{References}

1 A. Chabrerie and P.M. Black, Ventricular shunts, J. Intensive Care Med., 17(5):218-229, 2002.

2 A. Brodbelt and M. Stoodley, CSF pathways: a review, Brit. J. Neurosurg., 21(5):510-520, 2007.

3 J.M. Drake, J.R.W. Kestle, and S. Tuli, CSF shunts 50 years on-past, present, and future, Childs Nerv. Syst., 16:10-11, Nov. 2000.

4 Medtronic, "Neurological Products: Shunts," Medtronic, 8 Oct 2012. [Online]. Available: http://www.medtronic.com/for-healthcare-professionals/products-

therapies/neurological/shunts/index.htm. [Accessed 25 May 2014].

5 Codman, "Hydrocephalus Catalog," 2006. [Online]. Available: http://implantesclp.com/uploads/pdf/Codman.pdf. [Accessed 4 October 2014]

6 G.K. Reddy, P. Bollam, and G. Caldito, Long-Term Outcomes of Ventriculoperitoneal Shunt Surgery in Patients with Hydrocephalus, World Neurosurg., 81(2):404-410, 2013.

7 J.J. Stone, C.T. Walker, M. Jacobson, V. Phillips, and H.J. Silberstein, Revision rate of pediatric ventriculoperitoneal shunts after 15 years, J. Neurosurg.: Pediatrics, 11(1): 15-19, 2013.

8 J. M. M. B. Drake, J. R. M. Kestle and R. M. Milner, Randomized Trial of Cerebrospinal Fluid Shunt Valve Design in Pediatric Hydrocephalus, Neurosurg., 43(2): 294-303, 1998.

9 M. Czosnyka, Z. Czosnyka, H. Whitehouse, and J.D. Pickard, Hydrodynamic properties of hydrocephalus shunts: United Kingdom shunt evaluation laboratory, J. Neurol. Neurosurg. Psychiatry, 62(1): 43-50, Jan. 1997.

10 Z.H. Czosnyka, K. Cieslicki, M. Czosnyka, and J.D. Pickard, Hydrocephalus shunts and waves of intracranial pressure, Med. Bio. Eng. Comput., 43(1): 71-77, Jan. 2005.

11 J. Oh, G. Kim, F. Kralick, and H. Noh, Design and fabrication of a PDMS/parylene microvalve for the treatment of hydrocephalus, IEEE/ASME J. Microelectromech. Syst., 20(4):811-818, 2011.

12 S. B. Johansson, A. Eklund, J. Malm, G. Stemme, and N. Roxhed, A MEMS-based passive hydrocephalus shunt for body position controlled intracranial pressure regulation, Biomedical Microdevices, 16: 529-536, 2014.

13 I.M. Elixmann, M. Kwiecien, C. Goffin, M. Walter, B. Misgeld, M. Keifer, W-I. Steudel, K. Radermacher, and S. Leonhardt, Control of an electromechanical hydrocephalus shunt - a new approach, IEEE. Tran. Biomed. Eng., 61(9): 2379-2388, 2014. 
14 H.N. Schwerdt, R. Bristol, and J. Chae, Miniaturized Passive Hydrogel Check Valve for Hydrocephalus Treatment, IEEE Trans. Biomed. Eng., 61(3): 814-820, March 2014.

15 S. S. Je, J. Chae, A compact, low-power, and electromagnetically actuated microspeaker for hearing aids, IEEE Electron Device Letters, 29: 856-858, Aug. 2008.

D. Kim and D. Beebe, A bi-polymer micro one-way valve, Sens. Actuators A, 136:426-433, 2007.

17 R. Lo, P. Li, S. Saati, R.N. Agrawal, M.S. Humayan, and E. Meng, A passive MEMS drug delivery pump for treatment of ocular diseases, Biomed. Microdevices, 11:959-970, 2009.

18 J. Montheard, M. Chatzopoulos, and D. Chappard, 2-Hydroxyethyl methacrylate (HEMA): chemical properties and applications in biomedical fields, J. Macromol. Sci. Part C, 32(1): 134, 1992.

19 G. Kotzar, M. Freas, P. Abel, A. Fleischman, S. Roy, C. Zorman, J.M. Moran, and J. Melzak, Evaluation of MEMS materials of construction for implantable medical devices, Biomaterials, 23(13): 2737-2750, 2002.

20 C. Hassler, T. Boretius, and T. Stieglitz, Polymers for neural implants, J. Polymer Sci. Part B: Polymer Physics, 49(1): 18-33, 2010.

21 S. Timoschenko, Theory of Plates and Shells. McGraw-Hill, New York, 1940.

22 H. Li, T.Y. Ng, Y.K. Yew, and K.Y. Lam, Modeling and simulation of the swelling behavior of pH-stimulus-responsive hydrogels, Biomacromolecules, 6(1): 109-120, 2004.

23 S.H. Gehrke, G.P. Andrews, and E.L. Cussler, Chemical aspects of gel extraction, Chem. Eng. Sci., 41(8): 2153-2160, 1986.

I. Tranoudis and N. Efron, Tensile properties of soft contact lens materials, Contact Lens and Anterior Eye, 27(4): 177-191, 2004.

25 A. Quddos, H.U. Rehaman, A. Wadood, S. Sulfiqar, and M.L. Mirza, The effect of crosslinking agents on the synthesis and swelling of the polymer networks, J. Chem. Soc. Pakistan, 25(4): 299-304, 2003.

H. Bruus, Theoretical Microfluidics. Oxford University Press, New York, 2007.

27 F. Yetkin, U. Kayabas, Y. Ersoy, Y. Bayinder, S.A. Toplu, and I. Tek, Cerebrospinal fluid viscosity: a novel diagnostic measure for acute meningitis, Southern Med. J., 103(9): 892 895, 2010.

28 M.J. Lesho, and N.F. Sheppard, Jr., Adhesion of polymer films to oxidized silicon and its effect on performance of a conductometric pH sensor, Sensors and Actuators B, 37: 61-66, 1996. 
29 Q. Garrett, B. Laycock, and R.W. Garrett, Hydrogel lens monomer constituents modulate protein sorption, Invest. Ophth. Vis. Sci., 41(7): 1687-1695, 2000.

30 H.L. Brydon, G. Keir, E.J. Thompson, R. Bayston, R. Hayward, and W. Harkness, Protein adsorption to hydrocephalus shunt catheters: CSF protein adsorption, J. Neurol. Neurosurg. PS., 64(5): 643-647, 1998.

31 H.L. Brydon, R. Bayston, R. Hayward, and W. Harkness, The effect of protein and blood cells on the flow-pressure characteristics of shunts, Neurosurg., 38(3): 498-505, 1996.

32 H. Reiber, Flow rate of cerebrospinal fluid (CSF) - a concept common to normal blood-CSF barrier function and to dysfunction in neurological diseases, Journal of the Neurological Sciences, 122: 189-203, 1994.

33 V.R. Tirumala, R. Divan, D.C. Mancini, and G.T. Caneba, Fabrication of high-aspect-ratio hydrogel microstructures, Microsyst. Tech., 11:347-352, Apr. 2005.

34 Y. Yang, and J. Chae, Miniaturized protein separation using a liquid chromatography column on a flexible substrate, Journal of Micromechanics and Microengineering, 18:125010, Oct. 2008. 
Figure and Table Captions

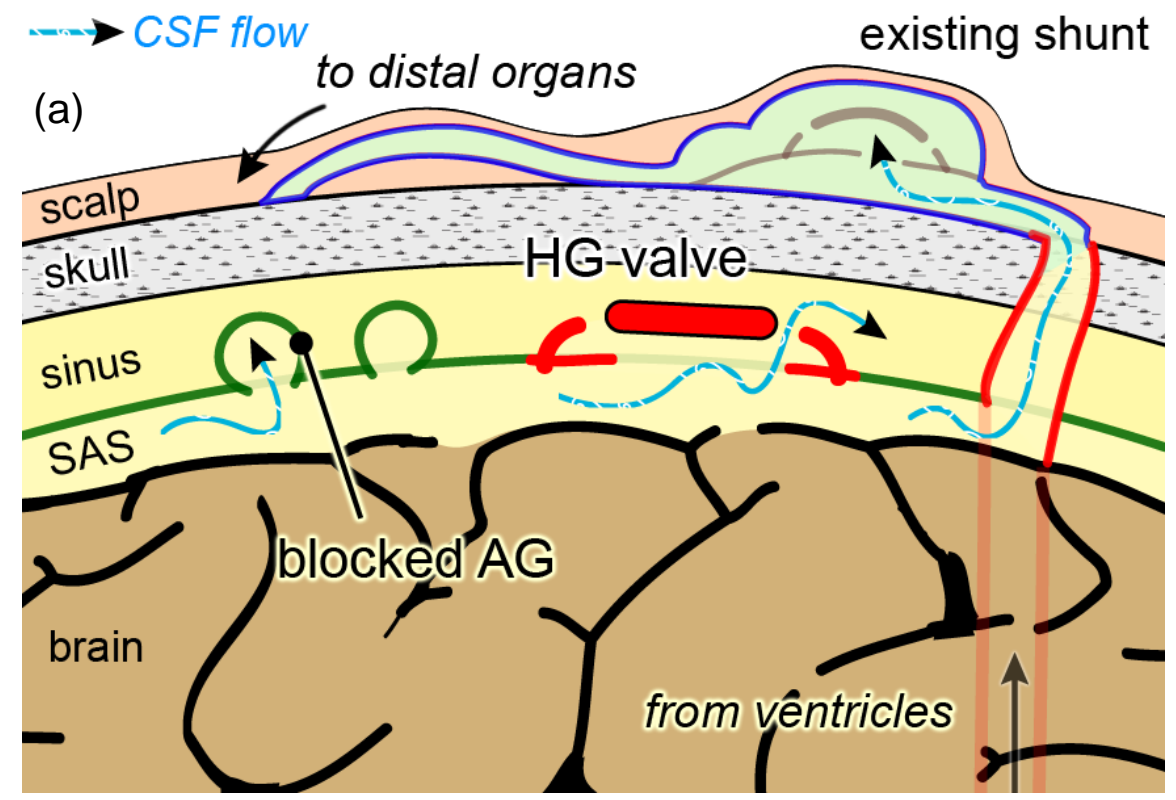

(b)

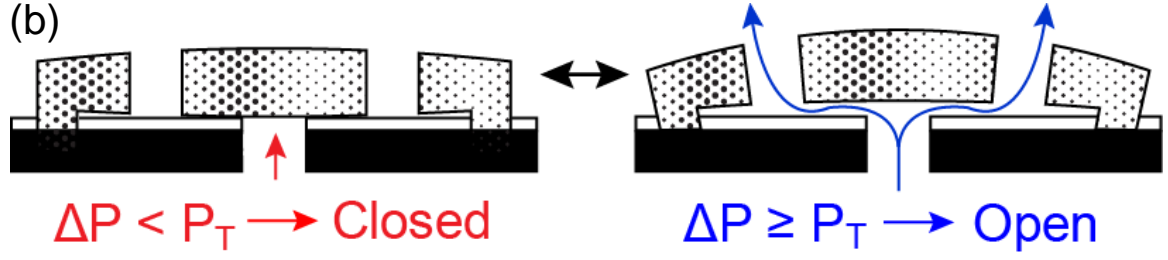

Figure 1. (a) Obstructed CSF flow in hydrocephalus and methods to introduce alternative CSF draining channels (existing shunt treatment approach and hydrogel, hydrogel, valve of this work). Arrows indicate CSF flow. Arachnoid granulations (AG) function as a one-way valve to drain CSF under normal conditions where intracranial pressure (ICP) and are blocked in hydrocephalus as seen in the left. Existing shunts require catheters from ventricles inside the brain or within the subarachnoid space (SAS) that protrude the skull to drain CSF outwards to distal organs. The proposed synthetic hydrogel valve, may provide more natural and less intrusive draining to alleviate hydrocephalus by creating CSF transport channels directly at the meninges and encased within the cranium. (b) Basic operation of the hydrogel valve in its designated closed and open states (cross sectional view). The hydrogel valve swells when it is immersed in liquid to provide a natural seal against the inlet and firmly close the valve seat to 
block flow when $0<\Delta P<P_{T}$, meaning the pressure at the sinus is nearly the same or higher than that at the SAS (left). When $\Delta P \geq P_{T}$ and the pressure observed in the SAS becomes higher than the venous draining area or sinus, the hydrogel valve seat deflects upwards to allow CSF to flow through the perforations.

TABLE I

SUMMARY OF DESIGN PARAMETERS OF MINIATURIZED VALVE

\begin{tabular}{ccc}
\hline \hline Design Variable & Symbol & Value \\
\hline Hydrogel diaphragm flexure & & \\
Young's modulus & $E$ & $10-150 \mathrm{kPa}$ \\
thickness & $t$ & $200-500 \mu \mathrm{m}$ \\
flexure length & $L_{f}$ & $1400-2000 \mu \mathrm{m}$ \\
flexure width & $W_{f}$ & $100-200 \mu \mathrm{m}$ \\
center diaphragm radius & $r_{o}$ & $500-600 \mu \mathrm{m}$ \\
Silicon inlet orifice & & \\
radius & $r_{i}$ & $200-400 \mu \mathrm{m}$ \\
length & $L_{i}$ & $500-750 \mu \mathrm{m}$ \\
\hline \hline
\end{tabular}

Table 1. Valve design parameters. 

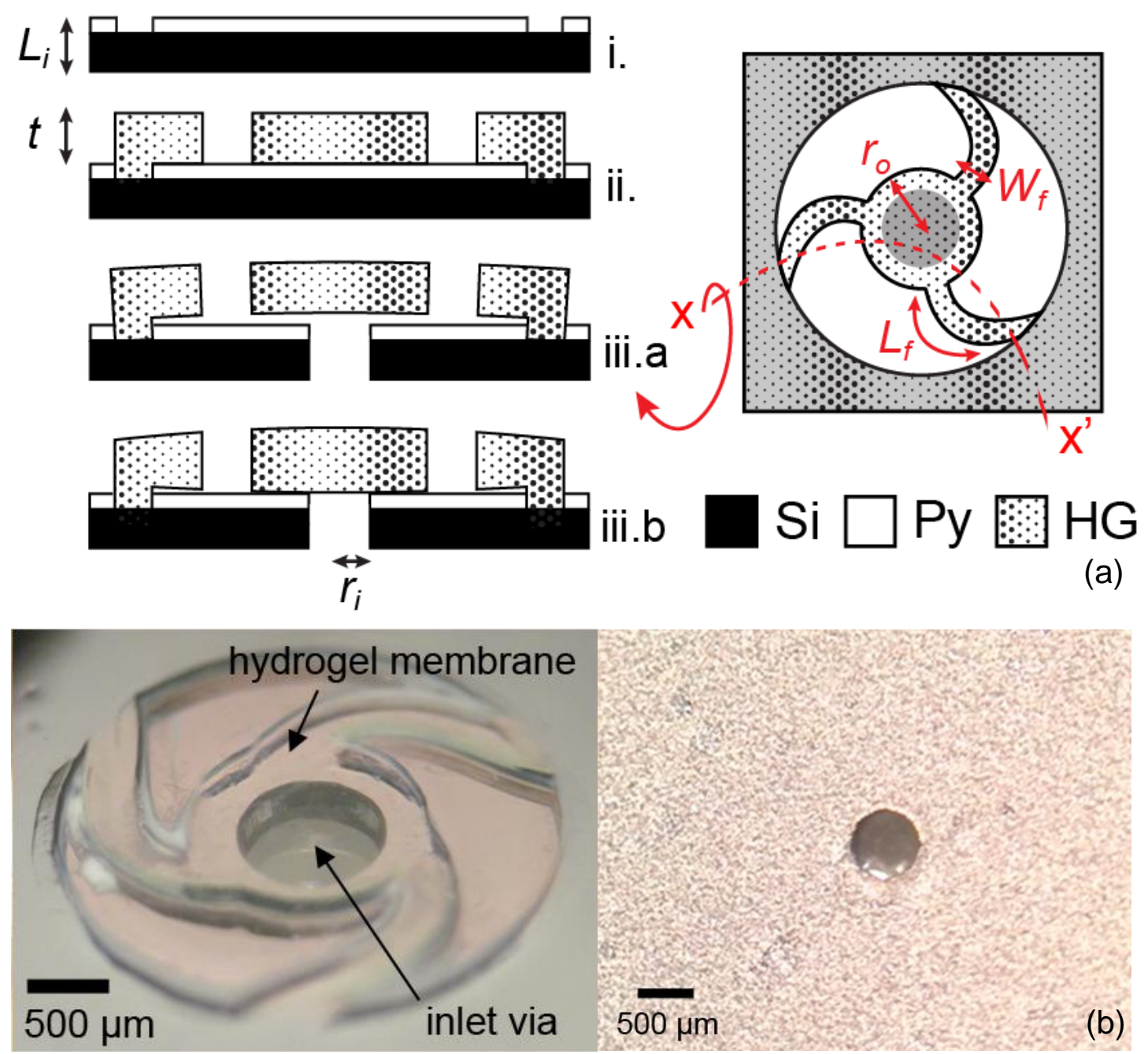

Figure 2. (a) Schematic workflow of fabrication process (cross-sectional: left and topside view: right). (i) $0.5-2.0 \mu \mathrm{m}$ parylene (Py) negative-anchor films deposited on $\mathrm{Si}$ and patterned by RIE. (ii) Hydrogel (hydrogel) solution is poured and patterned by UV. (iii.a) Backside inlet formed by DRIE of Si and RIE of Py and (iii.b) then hydrated to swell hydrogel. (b) Photograph of fabricated valve (topside on left and backside on right). 


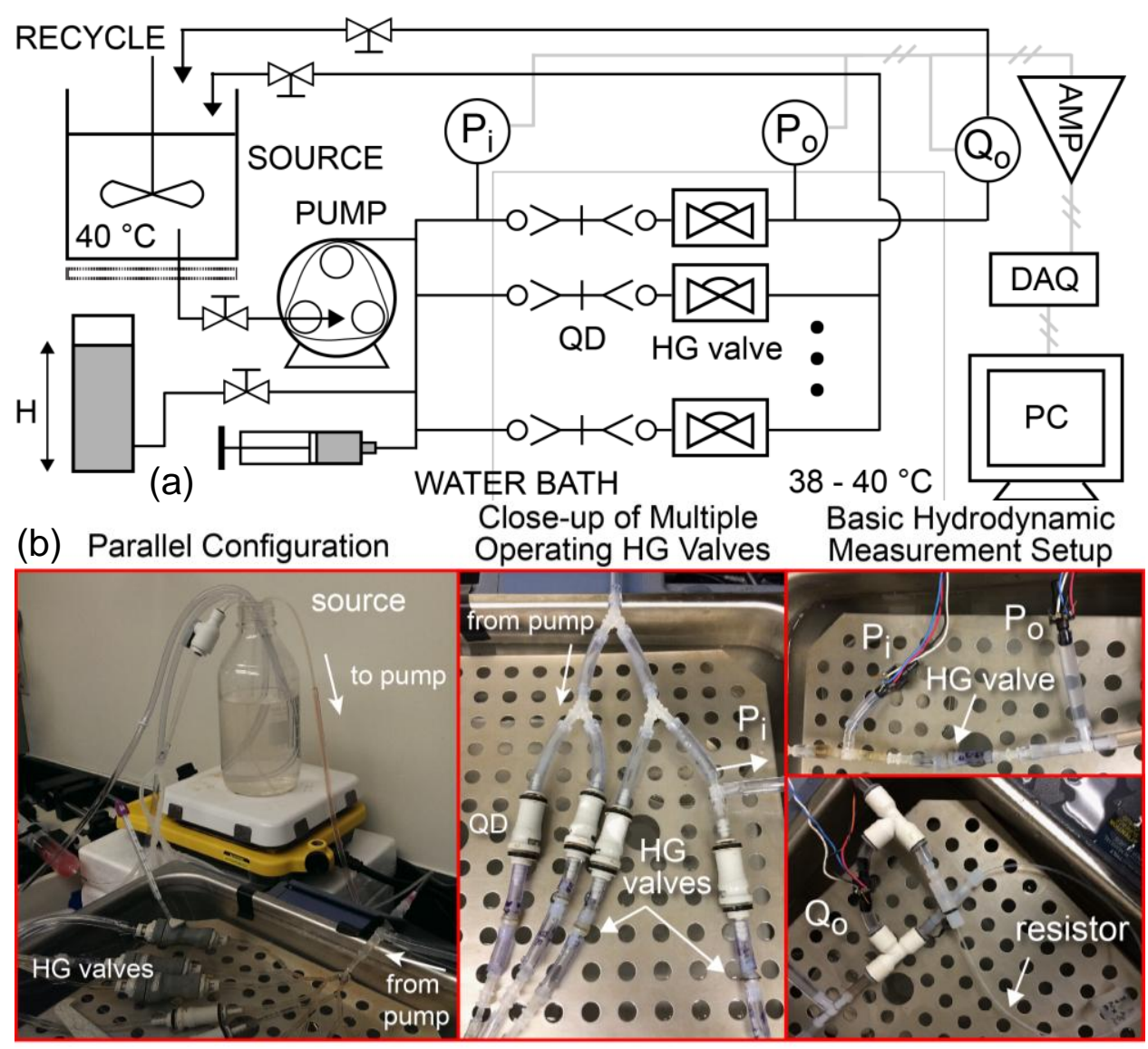

\begin{tabular}{lc}
\multicolumn{2}{c}{ SETTINGS FOR CONTINUOUS OPERATION AND CHARACTERIZATION } \\
\hline \hline \multicolumn{2}{c}{ Operational Parameter } \\
\hline Pump settings \\
RPM & Value \\
Data acquisition & 20 \\
Sampling rate & $1-10 \mathrm{kHz}$ \\
Samples read per buffer & $100-1000$ \\
Low pass filter cutoff & $40 \mathrm{~Hz}$ \\
Amplifier gain & $80-100$ \\
Measured pulsatile characteristics & \\
Peak to peak $\Delta P$ & $300-800 \mathrm{mmH}_{2} \mathrm{O}$ \\
Maximum $\Delta P$ & $450 \mathrm{mmH}_{2} \mathrm{O}$ \\
Minimum $\Delta P$ & $-350 \mathrm{mmH}_{2} \mathrm{O}$ \\
\hline \hline
\end{tabular}

Figure 3. (a) Experimental setup for valve characterization and concurrent parallel testing of multiple valves in hydrodynamic environment for over-time testing. A peristaltic pump is used to crudely recreate an accelerated form of pulsatile time-varying pressures of $1-4 \mathrm{~Hz}$ frequency, which is about $5-20$ times higher than the frequency of naturally occurring pressure waves in the brain. The amplitudes of the generated pressure waves are also much higher $(\sim 5-10$ times $)$ 
than those in the real head, on average. The peak to peak $\Delta P$ amplitudes ranged from $300-800$ $\mathrm{mmH}_{2} \mathrm{O}$ throughout continuous operation. (b) Photograph of different parts of experimental setup. The left photo shows a portion of the over-time setup including the source for the heated working fluid that is driven through the HG valves by means of a peristaltic pump (not shown) as indicated by the arrows. The middle photo shows a close-up of the multiple HG valves that undergo continuous operation in the water bath in parallel. The rightmost valve is connected to pressure and flow sensors to characterize the hydrodynamic characteristics generated by the pump. The right photo shows the setup for taking basic hydrodynamic measurements for individual $\mathrm{HG}$ valves by measuring pressure difference $\left(\triangle P=P_{i}-P_{O}\right)$ (top) and flow through a linear hydraulic resistor created by a small diameter semi-rigid tubing $\left(Q_{O}=\Delta P / R_{h}\right)$. (c) Tabulated operational settings configured or measured for semi-continuous setup and for valve characterization. 

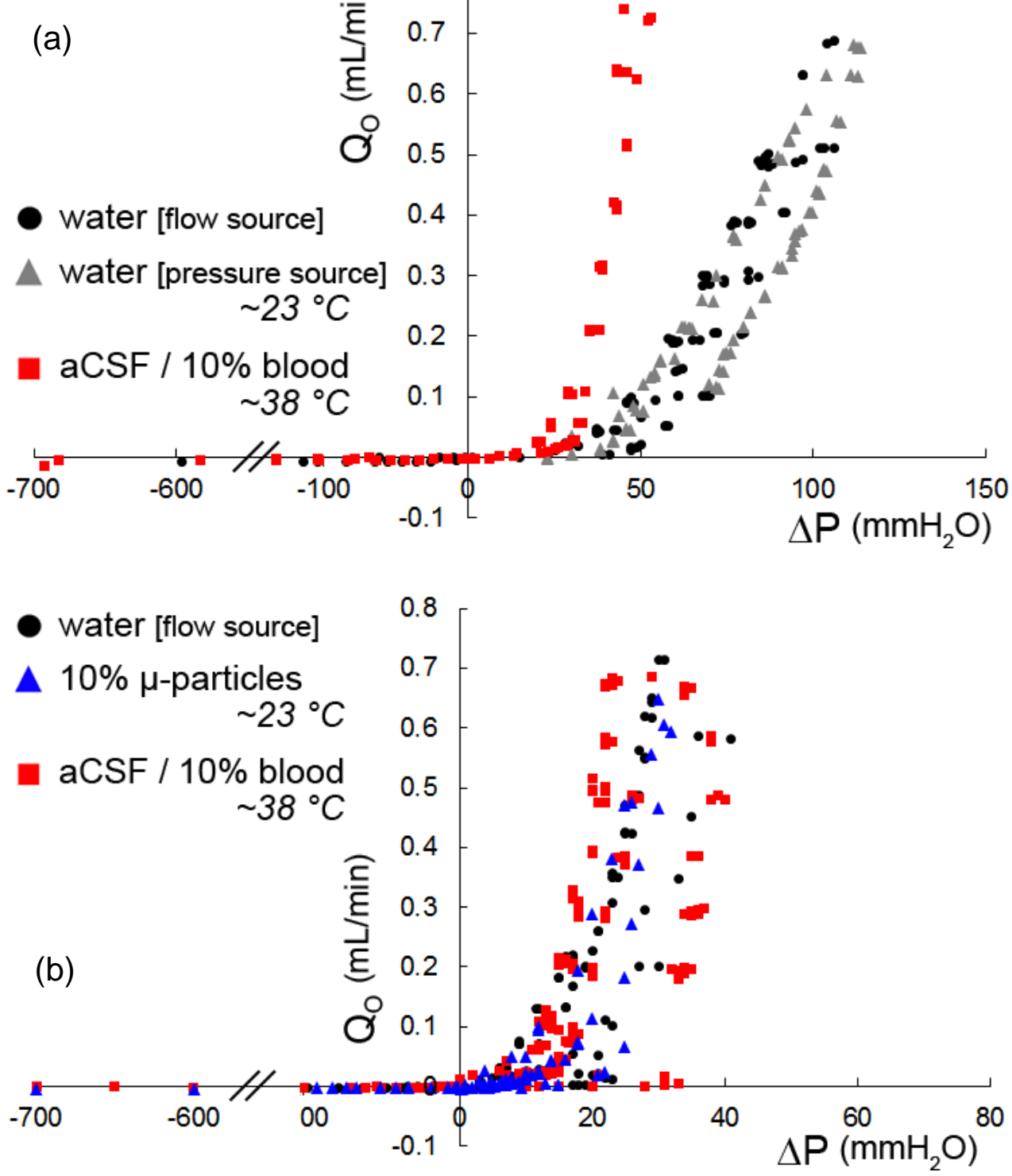


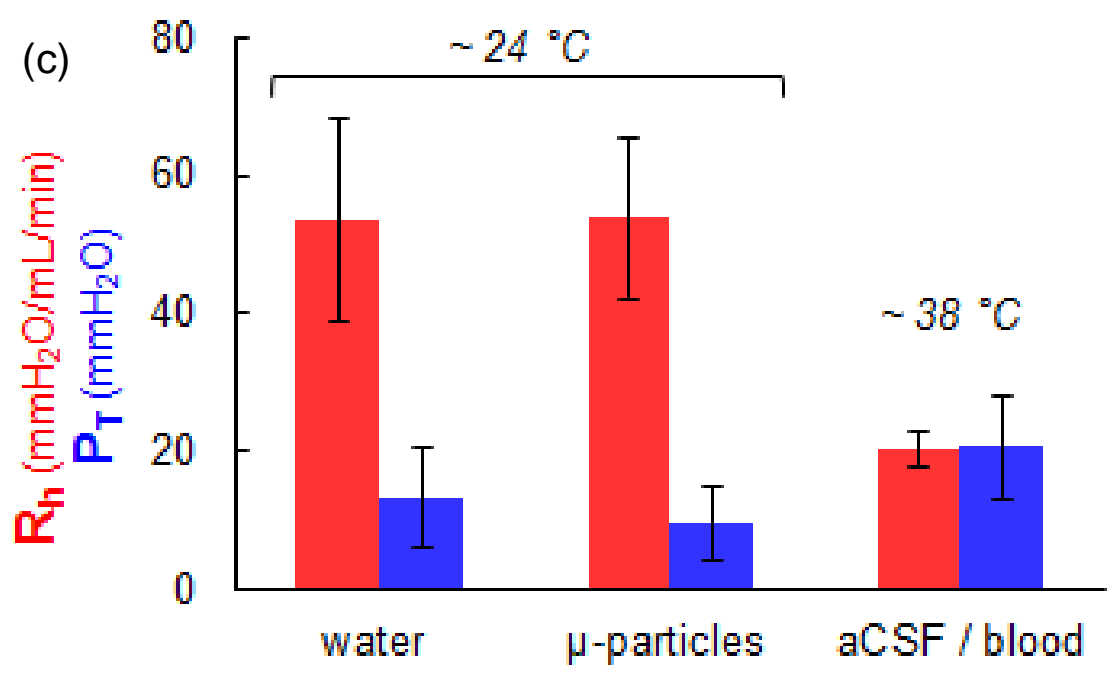

Figure 4. Hydrodynamic response of valves for different working environments and with different geometries. (a) Plot of flow $(\mathrm{mL} / \mathrm{min})$ versus pressure $\left(\mathrm{mmH}_{2} \mathrm{O}\right)$ for a valve with $t \sim$ $300 \mu \mathrm{m}, L_{f}=1.45 \mathrm{~mm}, W_{f}=200 \mu \mathrm{m}, r_{o}=550 \mu \mathrm{m}$, and $r_{i}=200 \mu \mathrm{m}$ in water at $\sim 23{ }^{\circ} \mathrm{C}$ and in emulated CSF with $10 \%$ blood at $\sim 38-40{ }^{\circ} \mathrm{C}$. Measurements in water are shown for data collected using both the pressure source and flow source to demonstrate the minimal variability in measured response. Pressure-flow curve is shifted during operation in heated emulated CSF solution, which is expected due to the lower viscosity and resultant lower $R_{h}$. (b) Pressure-flow response for a larger valve with $t \sim 250 \mu \mathrm{m}, L_{f}=2 \mathrm{~mm}, W_{f}=200 \mu \mathrm{m}, r_{o}=600 \mu \mathrm{m}$, and $r_{i}=250$ $\mu \mathrm{m}$ in water at $\sim 23{ }^{\circ} \mathrm{C}$, in a $10 \%$ microparticle aqueous suspension at $\sim 23{ }^{\circ} \mathrm{C}$, and in emulated CSF with $10 \%$ blood at $\sim 38-40{ }^{\circ} \mathrm{C}$. Although, measured $R_{h}$ decreases in the heated solution, the change is less noticeable relative to the smaller valve most likely due to the decreased dwelling of debris of imperfectly patterned hydrogel in exposed perforations, eliminating effects additional outflow resistance. (c) Evaluated range of $R_{h}$ and $P_{t}$ for valve in (b) in water at $\sim 23$ ${ }^{\circ} \mathrm{C}$, in a $10 \%$ microparticle aqueous suspension at $\sim 23{ }^{\circ} \mathrm{C}$, and in emulated $\mathrm{CSF}$ with $10 \%$ blood at $\sim 38-40{ }^{\circ} \mathrm{C}$. 

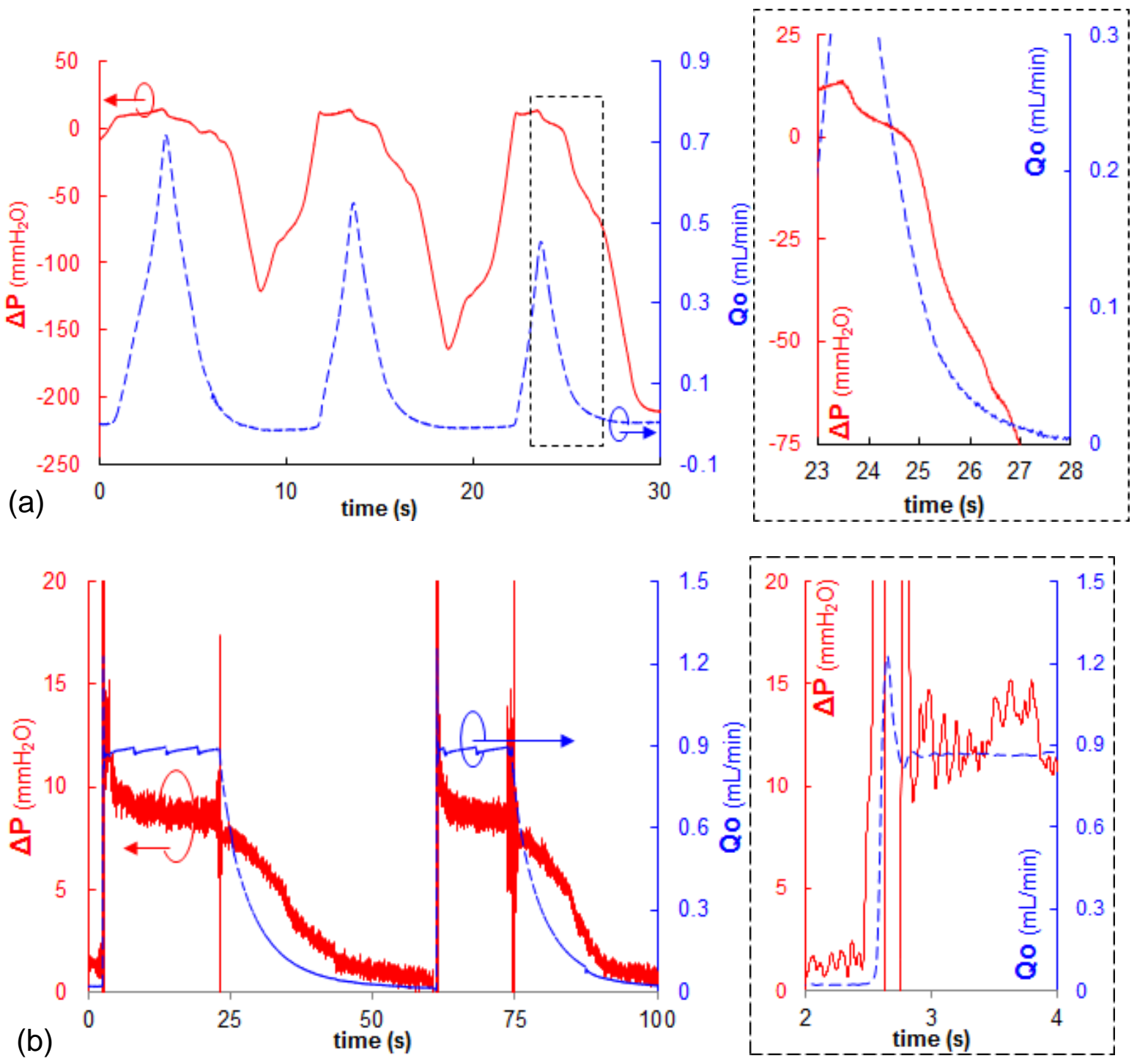

Figure 5. Transient response behavior: (a) Plot of $\Delta P$ and $Q_{o}$ versus time for a larger valve with $t$ $\sim 300 \mu \mathrm{m}, L_{f}=2 \mathrm{~mm}, W_{f}=200 \mu \mathrm{m}, r_{o}=600 \mu \mathrm{m}$, and $r_{i}=250 \mu \mathrm{m}$ responding to $0.1 \mathrm{~Hz}$ flow input triangular-like spike waveforms in emulated CSF with $10 \%$ blood at $~ 38-40{ }^{\circ} \mathrm{C}$. When $\Delta P<0, Q_{o}$ is maintained near zero, indicating a closed state. (Inset on right) About $\sim 2 \mathrm{~s}$ lag may be seen between $\Delta P$ reaching zero and $Q_{o}$ reaching zero. This lag is most likely due to the inertance of fluid between the flow sensor and hydrogel valve outlet. (b) Plot of same for response to manual valve switching to turn on/off a constant pressure source of $P \sim 240 \mathrm{mmH}_{2} \mathrm{O}$. 
Inset on right magnifies the switching event. Oscillatory behavior is due to manual control of switching valve.

(a)
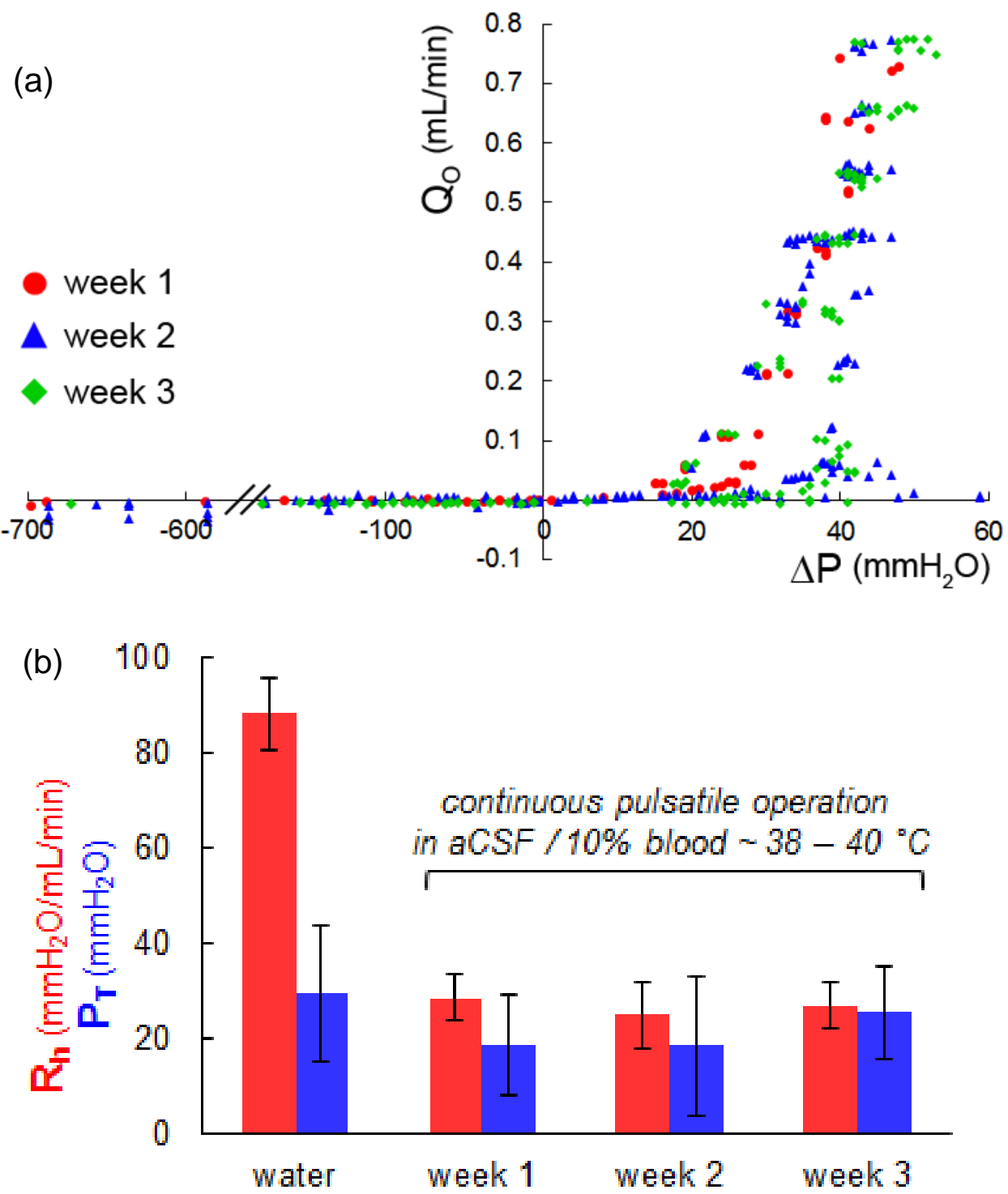

Figure 6. Overtime (3 weeks span) measurements of valves operating continuously under semiaccelerated conditions: (a) Hydrodynamic response measurements for same valve as Figure 4(a) with $t \sim 300 \mu \mathrm{m}, L_{f}=1.45 \mathrm{~mm}, W_{f}=200 \mu \mathrm{m}, r_{o}=550 \mu \mathrm{m}$, and $r_{i}=200 \mu \mathrm{m}$ as operated and measured in emulated CSF with $10 \%$ blood at $\sim 38-40{ }^{\circ} \mathrm{C}$. (b) Evaluated range of $R_{h}$ and $P_{t}$ for the overtime operated valve in the emulated CSF with $10 \%$ blood at $\sim 38-40{ }^{\circ} \mathrm{C}$ and in the initial water environment at $\sim 23^{\circ} \mathrm{C}$. 


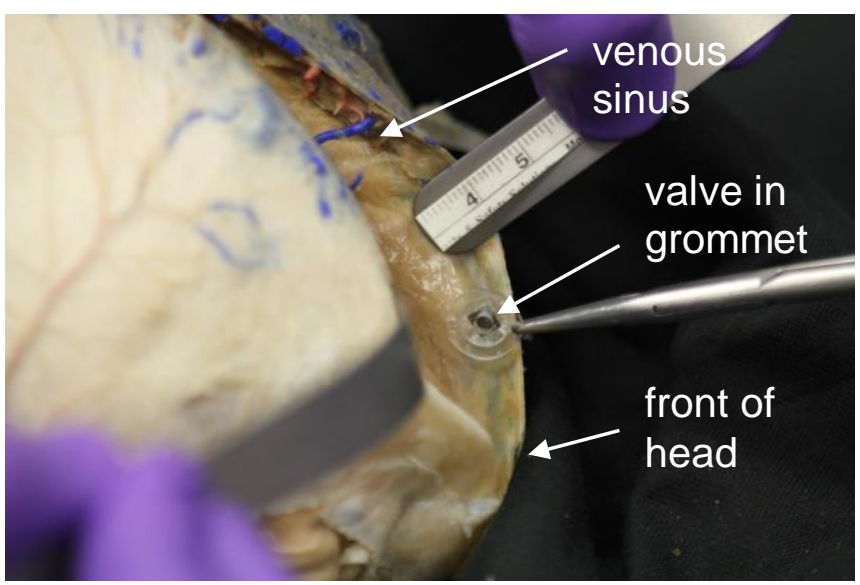

Figure 7. Valve placement in human cadaveric head. As the area of the top of the head contains too many bridging veins, as seen in the photo (dyed in blue color), the area more towards the front of the head is potentially more suitable as there occupies a larger sinus structure and fewer veins.

\begin{tabular}{lcc}
\hline \hline & Targeted & Measured \\
\hline$\Delta P$ & $-200-600 \mathrm{mmH}_{2} \mathrm{O}$ & $-800-300 \mathrm{mmH}_{2} \mathrm{O}$ \\
$Q_{o}$ & $0.1-3.0 \mathrm{~mL} / \mathrm{min}_{2}$ & $0.01-1.0 \mathrm{~mL} / \mathrm{min}$ \\
$P_{T}$ & $10-230 \mathrm{mmH}_{2} \mathrm{O}$ & $1-110 \mathrm{mmH}_{2} \mathrm{O}$ \\
$R_{h}$ & $81.5-136 \mathrm{mmH}_{2} \mathrm{O} / \mathrm{mL} / \mathrm{min}$ & $24-152 \mathrm{mmH}_{2} \mathrm{O} / \mathrm{mL} / \mathrm{min}$ \\
\hline \hline
\end{tabular}

Table 2. Summary of specifications for tested hydrogel valves. 